\title{
Ludusfera: o espaço do jogo
} hipermidiático ${ }^{1}$

Dóris Larizzatti²

1 Trabalho apresentado no Grupo de Trabalho Comunicação, Consumo, Entretenimento e Cultura Digital, do $2^{\circ}$ Encontro Comunicon, 2012.

2 Doutoranda em Ciências da Comunicação pela Escola de Comunicações e Artes da USP e mestre em Educação (PUC-SP)com especialização em Gestão da Comunicação (ECA-USP), e Sociologia do Lazer (UNICAMP). dorislarizzatti@gmail.com. 


\section{Resumo}

Investigação filosófico-teórica de abordagem interdisciplinar, que objetiva propor premissas à criação de ambientes digitais em hipermídias conceituais, como comunicação integrada, visando à compreensão inaugural de conceitos. A partir de contribuições temáticas, inspiradas em várias áreas do saber e fazer, apresentar nexos teóricos não conclusivos, mas possíveis lacunas e rupturas epistemológicas científicas, como frutos de uma reflexão sistemática centrada no processo criador de ambiências digitais interativas. Para tanto, objetiva-se a construção do metaconceito de Ludusfera, vista como esfera lúdica (espaço de jogo/Spielraum) de integração de experiências estéticas com conhecimento científico e cotidiano hipermidiático, sob a perspectiva da fenomenologia hermenêutica heidegger-gadameriana.

\section{Palavras-chave}

Ludusfera, jogo, hipermídia, ambiente digital.

\section{Abstract}

Philosophical and theoretical research with an interdisciplinary approach, which aims to propose the creation of open assumptions digital hypermedia concepts such as integrated communication, aimed at understanding inaugural concepts. From thematic contributions, inspired in various areas of knowledge, we propose to present not conclusive theoretical connections, but possible gaps and scientific epistemological ruptures, as fruits of unystematic reflection centered on the creative process for digital interactive ambiences. For this, it aims to build the meta-concept of Ludusfphere seen as a playful sphere (play space /Spielraum) of integration of aesthetic experiences with scientific knowledge and everyday hypermedia, from the perspective of phenomenology, hermeneutics Gadamer heidegger.

\section{Keywords}

Ludusphere, game, hypermedia, digital environment. 


\section{Do Homo sapiens ao ludens - imersão no ambiente hipermidiático}

Por meio de levantamento bibliográfico, identificamos que a maioria dos trabalhos no campo da hipermídia possui abordagem funcionalista, privilegiando seu uso técnico e utilitário em uma disciplina. Poucas são as linhas de pesquisa de instituições acadêmicas, com exceção da escola brasileira de Bairon (DAUD, 2006; GOSCIOLA, 2003; NERING, 2011; PETRY, 2010; PETRY, 2003), que se debruçam sobre conceitos numa perspectiva interdisciplinar, com embasamento filosófico-teórico, e demonstram critérios de análise em hipermídias para a ampliação do conhecimento científico, objetivos a que nos propomos. Nesse sentido, entendemos que o ser humano se constitui de forma lúdica e multimidiática, desde os seus primórdios, estabelecendo relações com o jogo ontológico (Spiel) que, por sua vez, compõe a natureza humana, pensamento que desenvolveremos rumo à investigação do metaconceito de Ludusfera, como espaço do jogo hipermidiático.

\section{Links históricos de um jogo: do Homo symbolicus ao media}

Se as linguagens, anteriores às mídias, surgem e se hibridizam, coexistem e se convergem na cronologia das épocas, interferindo nas visões de mundo, faz-se necessário registrar alguns aspectos históricos que antecederam as digitais, por meio das chamadas eras oral, escrita e imagética (LARIZZATTI, 2012). Numa sociedade oral primária, quase toda a construção cultural está fundada sobre as lembranças dos indivíduos, como exemplos: a escrita suméria e a cultura grega que, mesmo no auge da irradiação da escrita, apenas $13 \%$ dos gregos do século V sabiam ler e escrever (BAIRON; PETRY, 2000).

No dizer de McLuhan (1972) a Galáxia de Gutemberg, com a cultura do livro e do texto impresso, reinou soberana dos séculos XV ao XIX, sendo que os primeiros indícios para a expressão não linear emergiram em 1844, quando da invenção do telégrafo, que catalisou o desenvolvimento da linguagem jornalística. Já a era imagética, cujo início se deu desde a invenção da fotografia, 
intensificou-se no decorrer do século XX, com o cinema, a TV, o vídeo, a holografia e as imagens computacionais. Vale destacar que, nos anos 1980, surgiu uma tecnologia pré-internet e proto-hipermídia, o videotexto, com hibridismo de monitor de TV, telefone e computador (SANTAELLA, 2007, p. 289-291).

Se desejássemos representar uma breve história das mídias digitais até chegarmos à hipermídia, poderíamos configurar uma tela inicial, em que três nomes mereciam links para imersão: Vannevar Bush, Theodor Nelson e Douglas Engelbart, pois suas pesquisas precursoras resultaram na rede de alcance mundial, a Internet ou Word Wide Web. Vannevar Bush, matemático e físico renomado, considerado o primeiro a desenvolver um projeto visando o acesso multidirecional, a manipulação e a personalização da informação, chamou seu equipamento de Memex. Tal equipamento não chegou a ser construído, mas suas ideias foram fundamentais para o desenvolvimento de sistemas hipertextuais e hipermidiáticos que surgiram posteriormente (IDE, 1992). Além de Vannevar ter sido pioneiro no hipertexto, foi também o primeiro a vislumbrar o modo da mente humana se estruturar, espelhando-a em associações de dados armazenados em uma máquina (SALGADO, 2008, p.4).

Já o termo hipertexto foi criado no início dos anos 1960 por Theodor Nelson, filósofo e sociólogo envolvido com pesquisas na área de programação de computadores, a partir do vocabulário matemático, em que o prefixo "hiper" significa estendido e generalizado, influenciado pela noção de hiperespaço, espaço em quatro ou mais dimensões (BARDINI, 1997). A partir do Memex de Bush, formulou uma conceituação hipertextual como uma rede de trilhas associativas. Com Xanadu, seu grande projeto, aspirava criar uma rede de edição hipertextual, instantânea e universal, que preconiza a web atual (LÉVY, 1993, p. 29). Se Vannevar Bush idealizou o hipertexto, Theodor Nelson cunhou o referido termo, foi Douglas Engelbart quem o tornou operacional, além de ter sido conhecido como o inventor do editor de texto, do sistema de visualização por janelas e do mouse (LÉVY, 1993, p. 103). Conforme Lévy (1993, p. 51), foi Engelbart que propiciou o uso social da informática, criando um 
ambiente intuitivo, metafórico e sensório-motor, visando substituir o contexto abstrato, codificado, desprovido de sentido que se colocava entre o indivíduo e o computador no processo anterior. E quando dirigiu entre 1950 e 1960 o Augmentation Research Center (ARC), lançou os fundamentos dos sistemas atuais de nosso cotidiano: o mouse, as telas Windows, e o processador de texto, chamado Online System (NSL), para posteriormente operacionalizá-los via consoles (ELLIS, 1990). É possível perceber no trabalho de Engelbart a influência do pensamento de McLuhan (1964) sobre os meios de comunicação, como extensões dos órgãos humanos e seus impactos tecnológicos na própria natureza humana, bem como das ideias que orientaram a construção futura do Macintosh, entre outras inovações propostas por Steve Jobs.

Já a eletrônica surgiu no início do século XX, com os avanços da matemática e dos algoritmos. O protótipo de um computador digital apareceu em 1937, criado por John Vincent Atansoff. Desde então, o princípio fundamental da computação, baseada na díada 0/1, proposta por Leibnz três séculos antes, não sofreu alterações. Todas as fontes informacionais são homogeneizadas em cadeias sequenciais de 0 e 1 , ou seja, digitalizadas, e a sua transmissão independe do meio de transporte: fio de telefone, onda de rádio, satélite de TV, cabo etc. (SANTAELLA, 2011). Assim, nascia a Internet, sob o signo da academia, sendo desenvolvida por Tim Berners-Lee, no final das décadas de 1980 e começo de 1990, reunindo pesquisadores do mundo todo, para estudar e observar experimentos complexos na área de física. Um conjunto de soluções simplificadas foi o que Berners-Lee (1990) buscou para montar seu sistema: um software para publicar textos pela Web; o HTTP (Hypertext Transfer Protocol) e o HTML (HiperText Mark-up Language), que exemplificam o espírito central da Internet: descentralização, liberdade de adesão e expressão dos usuários, e valorização do intercâmbio de informações, de modo individual, comunitário, institucional ou acadêmico. 


\section{Ludus do Homo media: esferas filosófico-teóricas}

Refletir sobre contribuições filosófico-teóricas de abordagem interdisciplinar - modernidade líquida, semiosfera, interdisciplinaridade e esferas - para a construção do metaconceito de Ludusfera e suas relações com as demais palavras-chave: jogo, hipermídia e ambiente digital, destacando autores que compuseram tais referenciais, e objetivando demonstrar que a perspectiva do conceito é tridimensional, no sentido de ser hibridamente filosofia/teoria, teoria/método e método/técnica, para criação e construção do espaço do jogo hipermidiático. Seria então Ludusfera a palavra que revela a verdade encoberta por tantas outras palavras? Estaria ela a somar jogos potenciais de toda a ação humana, desde os primórdios? É fato que a modernidade líquida (BAUMAN, 2001) causou uma profunda mudança na condição humana, em seus modos de conhecer, trabalhar e educar, particularmente quando o espaço e o tempo são separados da prática da vida e entre si, a partir das novas tecnologias de informação e comunicação (NTICs). Fluímos e continuaremos a nos mover por causa da impossibilidade de atingir a satisfação de nossos desejos. Riscos e contradições no jogo da vida continuam a serem socialmente produzidos, mas o dever e a necessidade de enfrentá-los estão sendo individualizados na Ludusfera, fluída em suas expressividades digitais.

Já a semiosfera, concepção de cultura como espaço semiótico, foi formulada por Lotman para designar o habitat e a vida dos signos no universo cultural, ou seja, a totalidade da cultura imersa em um espaço semiótico, descontínuo, cujos temas só podem funcionar por meio da interação existente (LOTMAN; USPENSKIJ; IVÁNOV, 1981). Tal conceito derivou de outro anterior: biosfera, definido por Vernádski (1997) como a película que visa à conservação da matéria viva. Assim, a teoria da semiosfera ajuda-nos a refletir sobre os mecanismos básicos da constituição do espaço semiótico, tais como irregularidade, heterogeneidade, fronteira, transformação da informação em texto e, particularmente, o hibridismo - características fundamentais da cultura contemporânea, povoada de semiodiversidade (RISÉRIO, 2002). 
Ludusfera, portanto, seria o espaço do jogo contido dentro da evolução da semiosfera, mediante a exossomatização de signos e mídias eletrônicas e digitais, nas relações existentes.

Como interdisciplinaridade entendemos uma aspiração emergente de superação da racionalidade científica positivista e hegemônica, visando novas formas de produção de conhecimento, construção de paradigmas científicos inovadores, articulação da pluralidade dos saberes em torno de problemáticas comuns, desenvolvimento de trocas de experiências e modos de realização de parcerias do saber à comunidade, com indissociabilidade de pesquisa, docência e extensão (BAIRON, 2010, 2008, 2007a, 2007b, 2002). Por sua vez, a hipermídia é entendida, a partir da escola brasileira de Bairon, como um jogo originário de pesquisas acadêmicas, construído no interior de um projeto estético conceitual, ou seja, uma expressividade da linguagem que tem por objetivo a produção do conhecimento, como uma potencialidade reflexiva no meio acadêmico, baseada na exploração reticular de conteúdos teóricos e na inventariação multimidiática para oferecer aos usuários a possibilidade de jogar com uma estrutura analíticoconceitual. Nesse sentido, a Ludusfera pode ser utilizada como um método de interfaces entre diferentes áreas do conhecimento, por meio de uma abordagem lúdica, em que ser no mundo é jogar um jogo, e cada elemento em jogo ganha a sua determinação de ser.

Sobre a dimensão conceitual da comunicação nas esferas e a dimensão da experiência estética em sua expressividade hipermidiática, Bairon (2010) destaca a trilogia filosófica Esferas de Sloterdijk (1998, 1999, 2004), perpassando pela fenomenologia heideggeriana, como uma forma de compreensão da contemporaneidade, com base nos seguintes princípios: historicidade multifocal, linguagem hipermidiática, comunicação heterárquica e diálogo multiperspectivista. Em Esferas I - Bolha, Sloterdijk propõe um conceito com características topológicas, antropológicas e semiológicas. Trata-se da microesfera, cuja "expressividade mais consistente está calcada nos casais, nos pares e não no indivíduo" (BAIRON, 2010, p. 19); uma espécie de saber não 
sabido, mediante a experiência desde o útero, como uma "ginecologia filosófica". Já em Esferas II - Globo, "a linguagem que temos aqui se manifesta na saída da familiaridade (a cabana), passando pela cidade moderna e pelo império, até, finalmente, se expandir no espaço ilimitado e imensurável" (BAIRON, 2010, p. 20), identificando a globalização terrestre a que seguiu o perguntar metafísico e antecedeu o advento das telecomunicações digitais. Numa trajetória adversa às Esferas anteriores, Esfera III - Espumas destaca a "vida" que se desenvolve de modo reticular, hipermidiático e heterarquicamente, quando a comunicação, que só existe em mobilidade, articulando-se em cenários interconectados. Portanto, Ludusfera é filosoficamente a comunicação integrada entre as esferas, gerando espaço para mover-se e liberdade de movimento do jogador no mundo, conhecendo-se a si mesmo no outro.

Utilizamos também o termo Ludusfera como uma transliteração do alemão Spielraum, significado mais antigo de jogo (Spiel: interpretação, risco, brincadeira), que designa "espaço para mover-se, liberdade de movimento, espaço de jogo", segundo Heidegger (apud INWOOD, 2002, p. 101). Iniciemos com Duflo (1990) que, por meio de uma perspectiva histórica de Pascal a Schiller, desenvolve uma noção antropológica sobre o tema, mostrando que até o século XVIII existiam dois grandes gêneros de questões sobre o jogo, relativas ao seu valor ético ou aos seus aspectos epistemológicos. Na filosofia de Pascal, o jogo é concebido sob três formas: problema matemático, revelador moral e paradigma. Com Rousseau, o jogo ganha dignidade filosófica, com valor educativo. Em Kant, há uma mudança conceitual na análise do fenômeno lúdico, renovando-o filosoficamente em suas obras, com funções de: distrair ou educar, como parte do desenvolvimento humano: como registro de tempo, sinal, manifestação e tomada de posse por si da humanidade pelo infante: e em sua relação essencial com a sociabilidade e comunicação. Para Duflo, o século XVIII, além de "Século das Luzes", foi o "Século do Jogo".

Segundo Schiller, na esteira de Kant, o jogo se torna paradigma de sua antropologia, quando o homem é, sem coação, totalmente humano. Nesse 
momento, o tema lúdico passa a ser recorrente em textos de teólogos, filósofos, moralistas ou cientistas. Huizinga (1990), ao situar o lúdico como elemento da cultura, analisou que as grandes atividades arquetípicas da sociedade são, desde o início, marcadas pelo jogo, tais como a linguagem, esse primeiro e supremo instrumento que o homem forjou a fim de poder comunicar, ensinar e liderar. O conceito de jogo também foi trabalhado pela fenomenologia hermenêutica heidegger-gadameriana. Para Heidegger (2001) o filosofar pertence à essência da existência, que se expressa na linguagem cotidiana, ao "jogo da vida" no mundo. Segundo ele, jogar é anterior aos jogos, pois "não jogamos porque há jogos. Pelo contrário: há jogos porque jogamos" (Heidegger, 2001, p.324).

Já Gadamer (2008), influenciado por Platão, Hegel e no caminho de seu mestre Heidegger, define a hermenêutica como a arte de compreender, estabelecendo que o modo de ser da arte é o do próprio jogo. Para ele, todo jogar é um ser-jogado, sendo o jogo não uma recreação, mas uma ontologia, ideia oposta à racionalidade instrumental da ciência e tecnologia de nossa época. "Jogo de linguagem" também foi uma expressão que Wittgenstein (1989) utilizou para destacar a multiplicidade da linguagem, diferentemente da fixidez da forma lógica à definição do significado de uma palavra. Portanto, os novos critérios de conceituação serão fornecidos pelo uso que fazemos da linguagem nos mais diversos jogos, ou seja, nas diferentes formas de vida (MORENO, 2000).

Bairon (2007a, p. 97) pontua que, sob a perspectiva da fenomenologia heideggeriana, "devemos encarar a própria atividade do jogo como uma hipermídia, enquanto base tecnológica que é capaz de revigorar conceitos cada vez que ela é colocada em ação", com propostas interdisciplinares, desde seus fundamentos filosóficos às soluções técnicas respectivas, de modo que essa base tecnológica age como uma linguagem, na qual se realiza a compreensão e cuja realização se dá na interpretação. E "para a hermenêutica gadameriana, o modo de ser do jogo tem sua melhor existência como expressão na experiência estética", pois não se trata "do jogo com a linguagem, mas de jogos de linguagem, onde a mais consequente comunicação está no vaivém estético entre 
conhecimento científico e sensuscommunis", ou seja, um jogo de interpretações entre pesquisador e informantes, quando a realidade se apresenta pela aparência e pela ilusão (BAIRON, 2007a, p.102-103). Imersos nesse círculo filosófico é que contextualizamos nossa Ludusfera.

Por fim, almejamos ambientes digitais que sejam tanto interativos quanto imersivos, cujas narrativas digitais nos permitem interagir com elas, vivê-las num mundo mutável e caledoscópico, de natureza procedimental, participativa, espacial e enciclopédica, evidenciando o potencial multimidiático aplicado às práticas educacionais (MURRAY, 2003). Tais vivências também podem envolver a modelagem de objetos e ambientes tridimensionais, sua produção em entornos digitais, a reflexão sobre essas estruturas tridimensionais, sua metodologia, bem como a possibilidade dessa linguagem filosófica, teórica e metodológica, denominada "topofilosofia" por Petry (2003).

\section{Facultatis/udendi: paradigmas teórico-metodológicos em hipermídias}

Expor critérios avaliativos para propostas de criação e produção de trabalhos científicos em hipermídia, entre outras possíveis contribuições de interlocutores é a proposta. Bairon (2008) estabelece níveis de conhecimento como fundamentos epistemológicos da ciência: filosófico-teóricos (conceitos relacionados às teorias científicas em seus fundamentos filosóficos), teórico-metodológicos (fundamentos a partir da teoria definida pela pesquisa), metodológico-teóricos (opção conceitual teórica da pesquisa e sua exploração como metodologia) e técnicometodológicos (praticidade analítica dos conceitos teóricos para um método próprio da pesquisa). Tendo em vista a problematização sobre as tendências da linguagem científica contemporânea em expressividade digital, realizadas no Brasil e na Alemanha, em 2003, o pesquisador propôs uma taxionomia às estruturas digitais, com critérios de avaliação a partir de fundamentos teóricometodológicos e técnico-metodológicos: argumento (ambiente), entorno (bancos multimidiáticos com textos, imagens e sons) e relação entre soluções de programação e expressividade hipermidiática conceitual. 
Santaella (2005) define a hipermídia como uma linguagem interativa e, quanto maior for sua interatividade, mais profunda será a imersão do leitor. Através dessa exploração pode ser avaliado o teor criativo de uma produção hipermidiática: a isomorfia do seu desenho estrutural com o conteúdo que visa interagir. Ao incorporar esse potencial, aos outros poderes definidores da hipermídia - a hibridização das matrizes de linguagem com seus correspondentes modos de pensamento e a arquitetura dos fluxos informacionais, a pesquisadora apresenta uma versão didática de aplicação de sua teoria das três matrizes sonora, visual e verbal, e suas relações com as três categorias peircianas de primeiridade, secundidade e terceiridade.

Já Landow (1997) defende os roteiros de navegação ou navegabilidade para se avaliar uma hipermídia. Para tanto, faz-se necessário criar roteiros e programas capazes de guiar o leitor imersivo na navegação, ou seja, uma cartografia mental para um labirinto, a arquimetáfora da hipermídia. Partindo da navegação, Schulmeister (2001) propõe a interatividade com um parâmetro principal de análise hipermidiática, significando controlar o tema e o conjunto de conteúdos em produção em diferentes níveis: 1) ver e receber objetos; 2) assistir e receber múltiplas representações; 3) variar a forma de representação; 4) manipular o conteúdo dos componentes; 5) construir objetos ou representar conteúdos; e 6) construir objetos ou conteúdos de representação com recepção de feedbacks dos sistemas. Além desses pesquisadores, Gosciola (2003) apresenta elementos constitutivos da roteirização de mídias interativas - interatividade, navegação não linear e autoração, concorrendo para as intencionalidades conceituais que norteiam os processos criativos de hipermídias acadêmicas.

\section{Ludusfera: ambientes digitais em hipermídias conceituais}

A partir dos critérios avaliativos supracitados, o objetivo é iniciar uma demonstração do meta-conceito Lufusfera em cinco hipermídias, exemplificando graduais possibilidades criativas do uso do espaço de jogo em ambientes digitais 
para a compreensão inaugural de conceitos interdisciplinares do conhecimento científico em dialogia com nosso cotidiano multimidiático. Iniciemos com L'Ottocento, o último dos quatro volumes de Encyclomedia, de Umberto Eco (1999), que representam períodos da história da civilização europeia: séculos XVI, XVII, XVIII e XIX e abrangem aspectos da história política, econômica e social, ciência e tecnologia, artes visuais, literatura, teatro, música e cinema. Na ficha técnica dessa hipermídia constam 610 livros, 19 mil fichas, 2 mil imagens, 446 antologias de citações, 22 animações, 132 áudios musicais, 15 vídeos e 60 mil referências e livros para fichas.

Segundo Eco (1999, p.14), "embora não haja um projeto de pesquisa, uma pergunta específica a se formular, poderá navegar à ventura, como se jogasse e, realizando encontros inesperados, descobrirá pouco a pouco o tecido de um século". O entorno é uma biblioteca (ambiente intelectual e restrito). Por se tratar de uma enciclopédia virtual, a reticularidade é pouco explorada, por exemplo: há uma linha do tempo cronológica como uma sucessão de fatos. Quanto à navegação, há satisfação de interação com a obra, porém os hipertextos deixam lacunas. Com relação à interatividade (nível 4), existe a possibilidade de o leitor selecionar conteúdos escritos e criar seu próprio mapa de navegação. Já no hibridismo, há predominância das matrizes verbal e visual, em caráter ilustrativo (NERING, 2011, p.131-140).

Leonardo - o inventor (1996) foi uma das primeiras hipermídias lançadas na Feira de Frankfurt em 1994, composta por mais de 445 arquivos de áudio, 148 arquivos de vídeos e imagens e 95 arquivos de textos, portanto com predomínio da matriz sonora (DAUD, 2006). O argumento são suas invenções musicais, destacando sua "viola-organista", com afinação no modo "dórico", iniciando pela nota ré característica. Assim, o áudio tem a função de complemento imprescindível do verbal e visual, não se limitando ao papel ilustrativo ou ambiental, como geralmente ocorre na maioria das hipermídias. Em seu aspecto visual, é rica em quantidade de imagens, mas não em variedade de tipos, sendo todas figurativas em nível de primeiridade. As escolhas imagéticas também 
foram coerentes com os séculos XV e XVI, tais como a codificação de regras precisas e proporções dos desenhos de Leonardo. No seu aspecto verbal, a maioria dos ícones de navegação dessa hipermídia é formada por palavras, sendo duplamente simbólicos, pois se constituem em índices sinalizadores e são convencionados pela linguagem da informática. É, porém, na bibliografia que o texto verbal aparece predominantemente com descrições indiciais e narrativas consecutivas (SANTAELLA, 2005), totalizando cerca de 150 temas para pesquisa relativos à vida e obra do autor, suas invenções e dados históricos do período do Renascimento, com mais de 7 mil anotações dos cadernos de Leonardo, mediante abordagem interdisciplinar de diversas ciências como matemática, arquitetura, medicina, anatomia, geografia, física, entre outras (DAUD, 2010). A programação interativa também apresenta efeitos improváveis ou randômicos, com destaque para as invenções de Leonardo, cujas transições são essencialmente lúdicas (DAUD, 2010).

Diadorim éa personificação de um menino que vive aventuras (argumento), integrando a hipermídia produzida para o Projeto História Local nos Processos de Alfabetização de Crianças, Jovens e Adultos, sob a coordenação de Iokoi e Bairon (2001), com financiamento pela FAPESP, de 1996 a 2000. Por reivindicação dos professores, a proposta foi que os alunos de escolas municipais resgatassem, por meio de histórias de seus familiares e antepassados, acontecimentos que influenciaram na construção social, política e econômica da referida cidade. O ambiente em 3D é uma típica escola de ensino fundamental do município, espaço em que o menino Diadorim vive suas histórias, possibilitando ao aluno reconhecer sua identidade comparando-a com sua trajetória.

Com predomínio da matriz visual, o banco de imagens (citadas, reticulares e manipuladas) é composto por mapas de diversos bairros, produzidos com desenhos dos alunos e por fotografias da cidade, incluindo pessoas, pinturas e vídeos, cuja linguagem é repleta de signos como projeção, escala e legenda. Tal abordagem possibilitou ao aluno tanto a compreensão do macro/micro: caminho do bairro para a cidade, ao estado e ao país, além de questões sociais fora do 
contexto escolar como o trabalho assalariado, os processos de industrialização e evolução do comércio da região. A matriz verbal também está presente por meio de textos e contos, ao passo que o banco de áudio (locuções em voz over, fragmentos de vozes e sons) procura caracterizar o burburinho de um ambiente escolar (DAUD, 2006). Já os critérios de navegabilidade com links de palavraschave, trilhas sequenciais e sistemas de busca (nível 3), além de interatividade com objetos imagéticos coletados na pesquisa e presentes no ambiente dessa hipermídia, são consequentes com a produção de conceitos teóricos e científicos, indo além da linguagem verbal-escrita.

Ilha Cabu é o resultado da tese de doutorado de Arlete Petry (2010). Trata-se de um game acadêmico em 3D, em que o jogo é um "elemento possibilitador e potencializador da autoria e da produção do conhecimento e, particularmente, da produção dessa nova linguagem, que é a hipermídia" (Petry, 2010, p.20). Estas são as três ilhotas homônimas (temas) que compõem a ilha (entorno). O método foi refletido durante o fazer, uma vez que se adapta ao objeto, contrariamente à concepção racionalista. Sua navegabilidade (nível 4) e interatividade atuam juntas, através de diversos elementos e puzzles interativos. Quanto ao hibridismo das linguagens, os bancos de imagens (citadas e reticulares) e de áudio (locuções e sons), além dos textos, criam efeitos de mudança de consciência e construção conceitual, com percepção das características do jogo em todo o processo, especialmente na construção do roteiro e nos momentos de tomada de decisões na produção da referida hipermídia.

Em Hipermídia, psicanálise e história da cultura (2000), para preencher todos os critérios avaliativos, a imagem magna escolhida por Bairon e Petry foi do labirinto, repleto de objetos em 3D. Bancos de memória imagética, com séculos de história da pintura e da arte, desfilam em uma galeria demonstrativa (terceiridade). Há também 64 lugares interativos, dentre os quais se encontram 30 conceitos de base que se remetem aos textos analíticos (nível 6). A navegabilidade se estabelece por três modalidades: palavra/frase, semântica e relação. O sistema conceitual é modular e inclusivo, sendo que o módulo 
maior conecta a psicanálise com a história da cultura, com domínio do discurso dissertativo de gigantes do pensamento do século XX como Heidegger e Gadamer, Freud e Lacan, Wittgenstein e Bakhtin. Nessa hipermídia integram-se diferentes mídias e linguagens, que lançam ao leitor imersivo "piscadelas secretas para fisgá-lo nessa aventura intelectual em que pensamento e êxtase sinestésico se enlaçam" (SANTAELLA, 2005, p.408).

\section{Ludusfera: considerações em jogo}

Procuramos apresentar nexos filosófico-teóricos e metodológicos não conclusivos, possíveis lacunas da investigação e rupturas epistemológicas do conhecimento científico, frutos da reflexão sistemática centrada no processo criador de ambiências digitais em hipermídias conceituais para o jogo da ciência e do mundo. A partir das metáforas de fluidez versus solidez, entendemos que as estruturas hipermidiáticas, vistas como arquiteturas líquidas, perfuram e abrem caminhos investigativos, mesmo diante da dureza paradigmática de alguns campos da ciência. Outra característica que distancia a escrita metodológicocientífica e a utilização da hipermídia é que nesse ambiente somente o deslocamento através da tecnologia digital é que promove o encontro entre a relativa "objetividade" da interpretação documental e os rigores teóricos do conhecimento científico.

Desse modo, quando nos referimos à Ludusfera como espaço do jogo hipermidiático, estamos estabelecendo uma visão tridimensional do metaconceito: uma dimensão conceitual da comunicação nas esferas filosóficoteóricas, uma dimensão comunicativa da experiência estética em sua expressividade hipermidiática e uma dimensão lúdica da hipermídia, na qual o jogo é seu modo de ser na esfera do mundo (significante heideggeriano da linguagem na qual habitamos), no movimento de vaivém lúdico, da trajetória reticular-circular da compreensão entre autor/leitor imersivo, para o encontro estético-topológico entre conhecimento e ludicidade. 


\section{Referências}

BAIRON, S. A Comunicação nas esferas: a experiência estética e a hipermídia. Cibercultura: Revista USP. São Paulo: USP, no. 86, jun/ago 2010, pp. 18-27. . A hipermídia como comunicação integrada e a retomada da experiência estética na produção do conhecimento. Tese (Livre Docência). PPGCOM USP, 2008.

. "A espuma da hipermídia". Colóquio Internacional de Ciberliteratura. PUC SP, jun. 2007a.

; RIBEIRO, J. S. "A linguagem hipermidiática como produção do conhecimento: relações interdisciplinares". In: Antropologia Visual e Hipermedia. Porto: Edições Afrontamento, 2007b, pp. 43-60.

. Interdisciplinaridade: educação, história da cultura e hipermídia. São Paulo: Futura, 2002.

; PETRY, L. C. Hipermídia, psicanálise e história da cultura. Making of.São Paulo: EDUCS/Mackenzie, 2000.

BARDINI, T. "Bridging the gulfs: from hypertext to cyberspace". Journal of Computer Mediated-Communication, v. 3, no. 2, 1997.

BAUMAN, Z. Modernidade líquida. Rio de Janeiro: Jorge Zahar, 2001.

BERNERS-LEE, T.; CAILLIAU, R. World Wide Web: proposal for a hypertext project 1990. Disponível em: http://www.w3.org/Proposal.html.

BUYTENDIJK, U. O jogo humano. In: GADAMER, H. e VOGLER, P. (Orgs.) Nova antropologia: o homem em sua existência biológica, social e cultural. São Paulo: EPU USP, 1977, v.4.

COMPANY,The Learning. Leonardo 2.0: o inventor.PFS: Windows works are trademark of Softkey Internacional, LNT544AP, CD-ROM, 1997. 
DAUD, D. C. N. A relação entre a hipermídia e a aprendizagem: uma abordagem construtivista. Dissertação de Mestrado. São Paulo: Mackenzie, 2006.

DUFLO, Colas. O jogo: de Pascal a Schiller. Porto Alegre: Artmed, 1999.

ECO, Umberto (Org.) "L’Ottocento". In: Encyclomédia. Roma: Horizons, 1999

ELLIS, David. New horizons in information retrieval. London: Library Association Publising, 1990.

GADAMER, H. Verdade e método I: traços fundamentais de uma hermenêutica filosófica. Petrópolis/RJ: Vozes, Bragança Paulista, 2008.

GOSCIOLA, V. Roteiro para novas mídias. São Paulo: SENAC, 2003.

HEIDEGGER, M. Introducción a la filosofia. Madrid: Cátedra Universitat de Valéncia, 2001.

HUIZINGA, J. Homo ludens. São Paulo: Perspectiva/EEDUSP, 1971.

IDE, B. Hypertext and hipermidia: the effects on libraries, patrons and information organizacion. Honors Thesis, School of Library Sciense and Instructional Technology Southern Connecticut State University, 1992.

INWOOD, M. Dicionário Heidegger. Rio de Janeiro: Jorge Zahar Editor, 2002.

IOKOI, Z M. G. (Coord); BAIRON, Sérgio. História local nos processos de alfabetização de crianças, jovens e adultos do município de Diadema. São Paulo. PLCD52505, CDROM. FAPESP, 2001.

LARIZZATTI, D. S. S. "Hipermídia: links históricos de um jogo". Revista Brasileira de História da Mídia, v. 1, 2012, pp. 117-127.

LANDOW, G. Hipertexto: la convergencia de la teoria crítica contemporánea y la tecnologia. Barcelona: Paidós Ibérica, 1997.

LÉVY, P. As tecnologias da inteligência: o futuro do pensamento na era da informática. São Paulo: Editora 34, 1993. 
LOTMAN, I; USPENSKIJ, Boris; IVÁNOV, V. Ensaios de Semiótica Soviética. Lisboa: Horizonte, 1981.

MCLUHAN, M. A galáxia de Gutenberg. São Paulo: Cia. Ed. Nacional, 1972. . Os meios de comunicação como extensões do homem. São Paulo: Cultrix, 1964.

MORENO, A. R. Wittgenstein: os labirintos da linguagem - ensaio introdutório. São Paulo: Moderna /UNICAMP, 2000.

MURRAY, J. H. Hamlet no Holodeck: o futuro da narrativa no ciberespaço. São Paulo: Itaú Cultural/UNESP, 2003.

NERING, É. M. Ciência em hipermídia: tramas digitais na produção do conhecimento. Dissertação (Mestrado), ECA USP, 2011.

PETRY, A. S. O Jogo como condição da autoria e da produção de conhecimento: análise e produção em linguagem hipermídia. PUC SP, 2010, (tese de doutorado)

PETRY, L. C. Topofilosofia: o pensamento tridimensional na hipermídia. PUC SP, 2003, (tese de doutorado)

RISÉRIO, A. "Em defesa da semiodiversidade". Galáxia - Revista Transdisciplinar de Comunicação, Semiótica, Cultura. São Paulo: PEPG em Comunicação e Semiótica, no. 3, 2002, pp. 19-26.

SANTAELLA, L. Transmutações da escrita em suporte digital. In: Anais do Enelin, 2011, pp. 1-9.

. Linguagens líquidas na era da mobilidade. São Paulo: Paulus, 2007. - Matrizes da linguagem e pensamento: sonora visual verbal aplicações na hipermídia. São Paulo: Iluminuras/FAPESP, 2005.

SCHULMEISTER, R. Taxonomy of Multimedia Components Interactivity: a contribution to the current metadata debate. 2001. Disponível em: http://www.zhw.uni-hamburg. de/pdfs/Interactivity.pdf. 
SLOTERDIJK, P. Esferas III - Espumas. Espanha: Casa Del Libro, 2004. . Esferas II - Globo. Espanha: Casa Del Libro, 1999. . Esferas I - Bolha. Espanha: Casa Del Libro, 1998.

VERNADSKY, W. La Biosphère. Paris: Diderot, 1997.

WITTGENSTEIN, L. Investigações filosóficas. Lisboa: Calouste Gulbenkian, 1989. 